\title{
REVERSÃO DE CHOQUE HIPOVOLÊMICO DECORRENTE DE HEMORRAGIA ARTERIAL DURANTE NEFRECTOMIA - RELATO DE CASO
}

\section{M.A. PERRONI ${ }^{1}$; S. RODASKI ${ }^{2}$; L.J. BARREIROS ${ }^{2}$; G.C. KASECKER ${ }^{1}$; S.D. GUÉRIOS ${ }^{3}$}

${ }^{1}$ Acadêmicos bolsistas PIBIC/CNPq/Universidade Federal do Paraná. ${ }^{2}$ Docentes do Departamento de Medicina Veterinária da Universidade Federal do Paraná. ${ }^{3}$ Mestranda do Ccurso de Pós-Graduação em Ciências Veterinárias da Universidade Federal do Paraná.

Uma fềmea canina, SRD, adulta, com $11 \mathrm{~kg}$, foi encaminhada para uma cirurgia experimental na disciplina de Técnica Operatória da UFPR, sendo realizada no rim esquerdo nefrotomia, nefrectomia parcial e total. A medicação pré-anestésica constou da administração (SC) de sulfato de atropina $(0,044 \mathrm{mg} / \mathrm{kg}$ ) e diazepam $0,4 \mathrm{mg} / \mathrm{kg}(\mathrm{EV})$. A indução e manutenção anestésica foi realizada com a associação de Quetamina $(5 \mathrm{mg} / \mathrm{kg})$ e Xilazina $(0,5 \mathrm{mg} / \mathrm{kg}) \mathrm{EV}$. No momento da pediculação de artéria e veia renal, com $120 \mathrm{~min}$. de anestesia ocorreu hemorragia arterial com grave hipovolemia. O paciente começou a apresentar sinais de choque hipovolêmico. Como medidas de controle foram aumentada a velocidade do fluido (ringer com lactato) para $80 \mathrm{ml} / \mathrm{kg} / \mathrm{h}$, e procedeu-se ventilação controlada artificialmente. Com $180 \mathrm{~min}$. de anestesia foi diminuída a velocidade de fluido para $40 \mathrm{ml} / \mathrm{kg} / \mathrm{h}$, sendo também administrada solução salina hipertônica a 7,5\% (4 ml/kg/h). O procedimento cirúrgico terminou com 195 min., quando então o animal recebeu dexametasona $(2 \mathrm{mg} / \mathrm{kg})$ e foi mantido sob fluidoterapia (ringer com lactato e glicose $5 \%$ ) e com máscara de oxigênio. Foi administrado Ketoprofeno ( $2 \mathrm{mg} / \mathrm{kg} \mathrm{IM})$ quando o animal se apresentava em decúbito esternal. A medicação pós-operatória constou da administração de Cefalotina $(30 \mathrm{mg} / \mathrm{kg}) \mathrm{e}$ Metronidazole (15 mg $/ \mathrm{kg}$ ) durante sete dias, além de Ketoprofeno durante quatro dias. A cicatrização primária da ferida permitiu a remoção da sutura no $7^{\circ}$ dia pós-operatório. Hemogramas controles foram realizados no primeiro dia, evidenciado a anemia, e no décimo terceiro dia, quando os valores retornaram aos níveis padrões. Os valores hematimétricos permitiram calcular uma perda de volume sangüíneo em torno de $525 \mathrm{ml}(48 \mathrm{ml} / \mathrm{kg}$ ). Apesar da literatura preconizar a reposição sangüínea quando o volume perdido ultrapassar $25 \mathrm{ml} / \mathrm{kg}$, nesses pacientes, a terapia permitiu a recuperação do animal. Convém salientar que o custo da transfusão sangüínea foi fator limitante. A anemia está sendo controlada com a administração de alimentação adequada contendo altos valores protéicos. O objetivo deste relato foi de enfatizar que no tratamento do choque hipovolêmico, além de prontamente controlar se a hemorragia, a reposição de volume deve ser rápida e que o conjunto de procedimentos realizados, bem como o monitoramento constante no trans e pós-operatório permitiram a estabilização do paciente. Para concluir, todos os esforços devem ser concentrados e dirigidos para a pronta estabilização do paciente em choque hipovolêmico e que, neste caso, o conjunto de procedimentos terapêuticos instituido, apesar de certas limitações, permitiu a recuperação do paciente. 